JPE 16-1-37

\title{
Research of an On-Line Measurement Method for High-power IGBT Collector Current
}

\author{
Liangdeng $\mathrm{Hu}^{*}$, Chi Sun ${ }^{\dagger}$, and Zhihua Zhao* \\ ${ }^{*}{ }^{\dagger}$ National Key Laboratory for Vessel Integrated Power System Technology, Naval University of Engineering, \\ Wuhan, China
}

\begin{abstract}
The on-line measurement of high-power IGBT collector current is important for the hierarchical control and short-circuit and overcurrent protection of its driver and the sensorless control of the converter. The conventional on-line measurement methods for IGBT collector current are not suitable for engineering measurement due to their large-size, high-cost, low-efficiency sensors, current transformers or dividers, etc. Based on the gate driver, this paper has proposed a current measuring circuit for IGBT collector current. The circuit is used to conduct non-intervention on-line measurement of IGBT collector current by detecting the voltage drop of the IGBT power emitter and the auxiliary emitter terminals. A theoretical analysis verifies the feasibility of this circuit. The circuit adopts an operational amplifier for impedance isolation to prevent the measuring circuit from affecting the dynamic performance of the IGBT. Due to using the scheme for integration first and amplification afterwards, the difficult problem of achieving high accuracy in the transient-state and on-state measurement of the voltage between the terminals of IGBT power emitter and the auxiliary emitter $\left(u_{\mathrm{Ee}}\right)$ has been solved. This is impossible for a conventional detector. On this basis, the adoption of a two-stage operational amplifier can better meet the requirements of high bandwidth measurement under the conditions of a small signal with a large gain. Finally, various experiments have been carried out under the conditions of several typical loads (resistance-inductance load, resistance load and inductance load), different IGBT junction temperatures, soft short-circuits and hard short-circuits for the on-line measurement of IGBT collector current. This is aided by the capacitor voltage which is the integration result of the voltage uEe. The results show that the proposed method of measuring IGBT collector current is feasible and effective.
\end{abstract}

Key words: Collector current, Driver, Emitter inductance, IGBT, Measurement, Short-circuit

\section{INTRODUCTION}

Power electronic converter systems have an important trend towards a combination of intelligence, middle-high voltage, large capacity, good maintainability and high reliability [1]. Among these, the high reliability of the system depends largely on the performance of the power switching devices. The gate driver is one of the key factors for enabling the power switching devices to display the best performance. At present, the traditional analog passive gate driver uses a fixed on-off resistor to implement IGBT drive control [2]. Since there exists an inherent contradiction between the switching loss and the switching performance, it is impossible to make a decoupling control for the rate of change in the collector voltage and the

Manuscript received Jan. 20, 2015; accepted Apr. 20, 2015

Recommended for publication by Associate Editor Sang-Won Yoon.

${ }^{\dagger}$ Corresponding Author: sunchi77@sina.com.cn

Tel: +86-136-6727-0090, Fax: +86-027-836-01907, Naval Univ. of Eng.

*National Key Laboratory for Vessel Integrated Power System Technology, Naval University of Engineering, China collector current [3]. As a result, the range of safe operation of the power devices is limited. Active gate drive technology refers to using an active device to inject the required gate current into or to impose a particular gate voltage on the IGBT gate [4]-[6]. Thus, it is possible to achieve a better compromise between the switching loss and switching performance of an IGBT. However, some inherent drawbacks still exist, which include: 1) a reduction in the reliability of the driver, in which there are a lot of internal components, and a large number of analog devices to realize a complex control function [7]; 2) the inability of an analog driver to record and store the IGBT electrical variables and operational status information, with the result that the system controller cannot effectively monitor and diagnose the IGBT running state and fault behavior [8]. On the basis of a high-speed and high-density FPGA, an intelligent digital IGBT gate drive controller has been developed which integrates a kind of control function with high-power IGBT digital active gate drive technology in order to increase the 


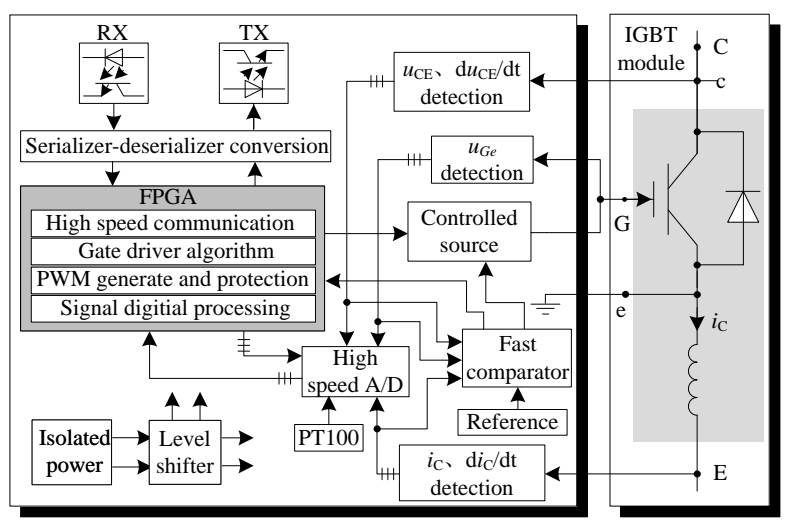

Fig. 1. Schematic drawing of intelligent digital IGBT gate drive controller.

reliability, maintainability and intelligence of the converter system. Its function diagram is shown in Fig. 1.

As shown in Fig.1, the digital circuits are the key components of the digital gate drive controller while some analog circuits are auxiliary. The analog circuits are mainly used for detecting and regulating the IGBT port electrical signal $\left(u_{\mathrm{CE}}, \mathrm{d} u_{\mathrm{CE}} / \mathrm{dt} 、 u_{\mathrm{Ge}}, i_{\mathrm{C}}\right.$ and $\left.\mathrm{d} i_{\mathrm{C}} / \mathrm{dt}\right)$. Then, the electrical signal sampled by the high-speed A/D will be sent to the FPGA for processing, storage and upload. What is worthy of note is that the communication interface of the digital controller only accepts control data like a modulation wave, which forms the drive signals with the locally-generated triangle carrier wave. Then, the driver can perform drive hierarchical control of the IGBT through the voltage source or current source to achieve the fast protection function of the IGBT with the hardware comparator as a core. Obviously, the IGBT port electrical signal detection is prerequisite and essential for the intelligent digital drive controller to fulfil the above functions [9]-[11]. Since the detection of IGBT collector current $i_{\mathrm{C}}$ is the basis of the digital drive controller used for IGBT driving hierarchical control, overcurrent and short-circuit protection, it plays an important role in the safe and stable operation of the IGBT and the whole converter system. On the one hand, the knowledge of what stage the IGBT is in during the process of its turn-on and turn-off through the collector current can lead to the driving hierarchical control and performance optimization of the IGBT. On the other hand, the detected IGBT collector current can be used to identify the IGBT running state, so as to improve the protection performance for the IGBT driver. In addition, the IGBT collector current data uploaded by the digital driver can lay the foundation for estimating the converter load current and using fewer sensors (which are still needed by the power supply inverter to detect and feed back the load voltage) or no sensors (based on a motor driver controlled by a no-speed sensor) for control. The result achieved will contribute to simplifying the secondary loop circuit, which reduces the cost of the hardware and improves the level of the modularization and standardization of the converter.

At present, IGBT collector current is detected in three primary ways as follows [12]: 1) using extra detecting elements such as a sensor [13], transformer [14], [15], PCB Rogowski coil [16], [17] or a magneto-resistive sensor to detect the collector current [18]. However, this leads to increases in both the structural complexity and the size of the power electronic converter, especially for converters with a laminated bus-bar structure. As a result, they are generally unavailable. 2) Using special types of IGBTs, for example, Infineon MIPAQ ${ }^{\mathrm{TM}}$ and Semikron Semitrans ${ }^{\circledR}$ IGBT, to detect the collector current with the help of a series resistor. However, a certain type of IGBT Mitsubishi or Powerex will cause the IGBT structure to become complex and increase its loss and cost when using the current mirror to obtain the collector current [19], [20]. In addition, only a small power IGBT can be used. 3) Measuring the collector current according to the IGBT port signal. Ref. [21] realizes a feedback control of the rate of change in the collector current by detecting the voltage between the terminals of the IGBT power emitter and the auxiliary emitter. However, it did not investigate collector current measurement. Ref. [22] points out that IGBT collector current can be obtained by integration according to the detected voltage drop between the terminals of the high-power IGBT power emitter and the auxiliary emitter. However, this method has defects: the integrating circuit is easily saturable and the integrated results are affected by the gate current. Therefore, it is impossible to make a measurement of IGBT on-state current. To date, no report has been found concerning its application to IGBT collector current measurement. Ref. [23] mentioned the measurement of capacitance voltage in a resistance-capacitance filter circuit paralleled with a IGBT power emitter and auxiliary emitter terminals for the estimation of the short-circuit current threshold. However, it failed to achieve the measurement of IGBT collector current.

In summary, there are defects in the existing methods of measuring collector current, such as higher costs, larger size, and a narrower measurement bandwidth. Therefore, these methods are not convenient for the online measurement of IGBT collector current. Based on the principle of the IGBT basic model [24], [25] and combined with the concept of short-circuit current threshold estimation [23], this paper has proposed a current measuring circuit for IGBT collector current.

The proposed circuit adopts an operational amplifier for impedance isolation to avoid the poor influence of the measurement circuit on the dynamic performance of the IGBT. Due to using the scheme of integration first and amplification afterwards, the difficult problem of achieving a high accuracy in the transient-state and on-state measurement of the voltage drop between the power-emitter and the auxiliary-emitter has been solved. On this basis, the adoption of a two-stage operational amplifier can better meet the requirement of high 
bandwidth measurement under the condition of a small signal with a large gain. Finally, various experiments are carried out under the conditions of several typical loads (resistance-inductance load, resistance load, and inductance load), different IGBT junction temperatures, soft short-circuits and hard short-circuits. The results show that the proposed circuit and on-line measuring method for IGBT collector current are feasible and effective.

\section{THE COLLECTOR CURRENT MEASURING CIRCUIT AND ITS PRINCIPLE}

\section{A. The Collector Current Measuring Circuit}

As shown in Fig.2, the high-power IGBT collector current measuring circuit contains $L_{\mathrm{E}}$ and $R_{\mathrm{E}}$ which denote the IGBT power emitter inductance and resistance, and $L_{\mathrm{e}}$ and $R_{\mathrm{e}}$ which denote the IGBT auxiliary emitter inductance and resistance, respectively. As can be seen from Fig.2, the voltage $u_{\mathrm{Ee}}$ of the IGBT power-emitter and auxiliary-emitter is connected to the $R_{\mathrm{f}}$ and $C_{\mathrm{f}}$ resistance capacitance integrating circuit after the impedance isolation of the operational amplifier $U_{1}$. The subsequent operational circuit amplifies the signal of the capacitor voltage $\mathrm{u}_{\mathrm{Cf}}$ in the integral circuit. The chip $\mathrm{U}_{1}$ is mainly used for signal impedance isolation, with a unit gain bandwidth up to $100 \mathrm{MHz}$. Chips $\mathrm{U}_{2}$ and $\mathrm{U}_{3}$ are mainly used for signal amplification, with both of their unit gain bandwidths being large than $300 \mathrm{MHz}$.

Because there is a huge difference in the amplitude of $u_{\mathrm{Ee}}$ when the IGBT is in a switching transient state and in a switching-on state, the conventional direct amplification measuring method is difficult to use for the accurate measurement of the transient-state and on-state $u_{\mathrm{Ee}}$. For this reason, the resistance capacitance integral method for $R_{\mathrm{f}}$ and $C_{\mathrm{f}}$ is used to measure the signal $u_{\mathrm{Ee}}$ indirectly. The transient amplitude of $u_{\mathrm{Cf}}$ is decreased after the integration of $u_{\mathrm{Ee}}$, while the on-state amplitude is accumulated by integration. Thus, it is possible to amplify and measure the signal $u_{\mathrm{Ee}}$.

Considering that the circuit for $u_{\mathrm{Ee}}$ integration and regulation may affect the dynamic performance of the IGBT, the measurement of $u_{\mathrm{Ee}}$ is made by operational amplifier impedance isolation and integration. The power-level voltage $\mathrm{u}_{\mathrm{Ee}}$ is transferred to the signal level for processing. As shown in Fig.2, $u_{\mathrm{Cf}}$ is the integration result of $u_{\mathrm{Ee}}$.

Since the amplitude of the signal $u_{\mathrm{Cf}}$ output by the integration of $u_{\mathrm{Ee}}$ remains very small $(<100 \mathrm{mV})$ and the frequency is considerably high (the highest frequency is up to $10 \mathrm{MHz}$ or more), it is hard for a conventional low voltage probe with about $10 \mathrm{mV}$ in measurement accuracy to meet the measurement requirements. To obtain an accurate signal $u_{\mathrm{Cf}}$ for estimation of the IGBT collector current $i_{\mathrm{C}}, u_{\mathrm{Cf}}$ needs to be highly magnified without distortion. However, it is difficult for the conventional single-stage operational amplifier to do so. To

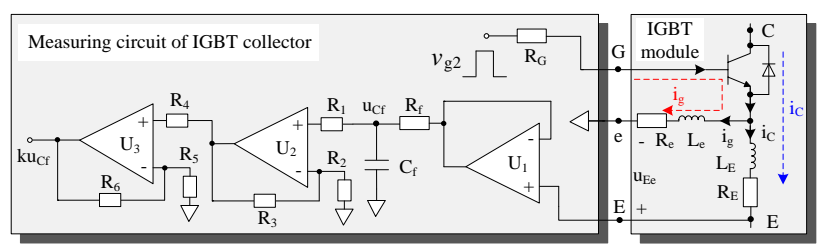

Fig. 2. Measuring circuit of IGBT collector.

solve these problems, a two-stage operational amplifier is applied to amplifying the $u_{\mathrm{Cf}}$ signal. The magnification set for each stage of the operational amplifier circuit is 11 times. Thus, the total magnification of the circuit is greater than 100 in order to meet the requirements of the oscilloscope measurement.

In view of the gain bandwidth product of chips $\mathrm{U}_{2}$ and $\mathrm{U}_{3}$, the circuit bandwidth is still more than $20 \mathrm{MHz}$ (with the bandwidth of a distortion free signal that is greater than $10 \mathrm{MHz}$ ), thereby meeting the measurement requirements of the signal $u_{\mathrm{Cf}}$. Using a two-stage amplifier, it is possible to achieve the high bandwidth measurement of a small signal with a lager gain.

\section{B. The principle of Collector Current Measurement}

According to Fig.2, the relationship between the voltage $u_{\mathrm{Ee}}$ and the collector current $i_{\mathrm{C}}$ is expressed as (1).

$$
u_{E e}=-\left(s L_{E}+R_{E}\right) i_{C}+\left(s L_{e}+R_{e}\right) i_{g}
$$

where $i_{\mathrm{g}}$ is the gate drive current existing in the switching transient of the IGBT, with an amplitude that is much smaller than that of $i_{\mathrm{C}}$. Meanwhile, $i_{\mathrm{g}}$ cannot be directly ignored because it is generally larger in its rate of change than $i_{\mathrm{C}}$ in the switching-on transient of the IGBT.

According to the principle of the operational amplifier and its related circuit, the relationship between signal $u_{\mathrm{Cf}}$ and signal $u_{\text {Ee }}$ is shown in (2).

$$
u_{C f}=u_{E e} /\left(R_{f} C_{f} s+1\right)
$$

Namely:

$$
u_{C f}=\frac{-\left(s L_{E}+R_{E}\right) i_{C}+\left(s L_{e}+R_{e}\right) i_{g}}{R_{f} C_{f} s+1}
$$

The variations of $i_{\mathrm{g}}$ and $i_{\mathrm{C}}$ are separate in time when the IGBT is in the switching-on transient-state. As a result, the capacitor $C_{\mathrm{f}}$ can be reset when $i_{\mathrm{g}}$ in the transient state before $i_{\mathrm{C}}$ is in the transient state, which removes the influence of $i_{\mathrm{g}}$ on the measuring result of $u_{\mathrm{Cf}}$. Then, (3) can be rewritten as:

$$
u_{C f}=-\left(s L_{E}+R_{E}\right) i_{C} /\left(R_{f} C_{f} s+1\right)
$$

As a result, the current $i_{C}$ can be expressed as:

$$
i_{C}=-\frac{u_{C f}\left(R_{f} C_{f} s+1\right)}{R_{E}\left(s L_{E} / R_{E}+1\right)}
$$

It is known from (5) that there exists a certain relationship between the voltage $u_{\mathrm{Cf}}$ and the current $i_{\mathrm{C}}$. Given appropriate parameter selection, $R_{\mathrm{f}} C_{\mathrm{f}}=L_{\mathrm{E}} / R_{\mathrm{E}}$ is established. Then, (5) can be rewritten as: 


$$
i_{C}=-u_{C f} / R_{E}
$$

As shown in Fig. 3, equation (5) represents the amplitude characteristic curve of $\mathrm{u}_{\mathrm{Cf}} / \mathrm{i}_{\mathrm{C}}$ [26]-[28].

Fig. 3 shows that for $L_{\mathrm{E}} / R_{\mathrm{E}}=R_{\mathrm{f}} C_{\mathrm{f}}$, (6) is valid in the entire angular frequency $(\omega=2 \pi f)$ ) range; for $L_{\mathrm{E}} / R_{\mathrm{E}}>R_{\mathrm{f}} C_{\mathrm{f}}$, (6) is valid in the range of $\omega<R_{\mathrm{E}} / L_{\mathrm{E}}$; and for $L_{\mathrm{E}} / R_{\mathrm{E}}<R_{\mathrm{f}} C_{\mathrm{f}}$, (6) is valid in the range of $\omega<1 /\left(R_{\mathrm{f}} C_{\mathrm{f}}\right)$.

It is learned from (5) that if $L_{\mathrm{E}} / R_{\mathrm{E}}=R_{\mathrm{f}} C_{\mathrm{f}}$, it is possible to perform the estimation of the IGBT collector current $i_{\mathrm{C}}$ by detecting the voltage of $u_{\mathrm{Cf}}$ in the whole frequency range according to (6).

The actual values of $\mathrm{R}_{\mathrm{f}}, \mathrm{C}_{\mathrm{f}}, \mathrm{L}_{\mathrm{E}}$, and $\mathrm{R}_{\mathrm{E}}$ are $150 \Omega, 1 \mathrm{uF}$, $4.3 n H$, and $28.5 \mu \Omega$, respectively. The variations of $R_{f}$ and $C_{f}$ are $1 \%$ and $5 \%$, depending on the accuracy of $R_{f}$ and $C_{f}$. The variation of $R_{E}$ mainly depends on its temperature. The inductance value of $\mathrm{L}_{\mathrm{E}}$ is basically unchangeable in the "on" state, while it will decrease in the switching transient.

According to the value-taken range of the practical high-power IGBT parameters, the analytic result of the amplitude-frequency characteristic of $\mathrm{u}_{\mathrm{Cf}} / \mathrm{i}_{\mathrm{C}}$ is obtained, as shown in Fig. 4. The parametric values of the Reference (Ref) curve in the figure are $R_{\mathrm{E}}=28.5 \mathrm{u} \Omega, R_{\mathrm{f}}=150 \Omega, C_{\mathrm{f}}=1 \mathrm{uF}$, and $L_{\mathrm{E}}=4.2 \mathrm{nH}$. The other curves express the results after the parametric value is changed according to the Ref curve. From the Ref curve value and the values of the other curve values, it is found that the ratio of $u_{C f} / i_{\mathrm{C}}$ is mainly influenced by $R_{\mathrm{E}}$. However, it is influenced little by the other parameters in low frequency range. The variation magnitude of $u_{C f} / i_{C}$ ranges from $2.35 \mathrm{u} \Omega$ to $3.6 \mathrm{u} \Omega$ in the whole frequency range. It is less than $\pm 30 \%$, when the phase variation is less than $\pm 4 \%$.

The accuracy of the on-line measurement of the collector current for the IGBT hierarchical protection is not high, while it needs temperature compensation for control with measured collector current.

In view of the peculiarities of $\mathrm{L}_{\mathrm{E}}$ and $\mathrm{R}_{\mathrm{E}}$, the method of actively injecting a larger collector current of strictly linear characteristics into the IGBT can be adopted. When a larger collector current flows through it, the voltage drop of $\mathrm{u}_{\mathrm{Ee}}$ between $L_{E}$ and $R_{E}$ becomes large. Compared with the $\mathrm{mA}$-level current injected according to the used impedance analysis, the high amplitude $\mathrm{u}_{\mathrm{Ee}}$ generated by the large current is easy to detect, without being easily disturbed by the measuring devices and other external factors.

When the IGBT is in the "on" state, the gate current is very small and can be ignored. The relationship between the collector current $\mathrm{i}_{\mathrm{C}}$ and $\mathrm{u}_{\mathrm{Ee}}$ can be expressed as (7).

$$
-u_{E e}=i_{C} \cdot R_{E}+L_{E} \cdot d i_{C} / d t
$$

The substitution of the values of $\mathrm{i}_{\mathrm{C}}$ and $\mathrm{u}_{\mathrm{Ee}}$ obtained at two minutes into (7) can determine the size of $L_{E}$ and $R_{E}$ by solving the simultaneous equation. Refer to expression (8).

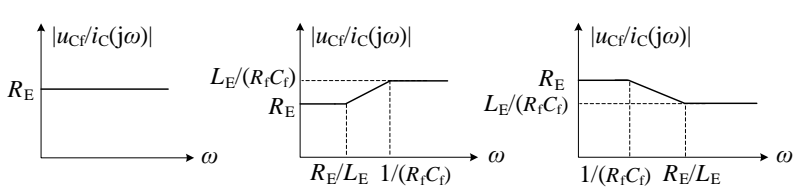
(a) $L_{\mathrm{E}} / R_{\mathrm{E}}=R_{\mathrm{f}} C_{\mathrm{f}}$
(b) $L_{\mathrm{E}} / R_{\mathrm{E}}>R_{\mathrm{f}} C_{\mathrm{f}}$
(c) $L_{\mathrm{E}} / R_{\mathrm{E}}<R_{\mathrm{f}} C_{\mathrm{f}}$

Fig. 3. Amplitude-frequency characteristic curve of $u_{\mathrm{Cf}} / i_{\mathrm{C}}$.

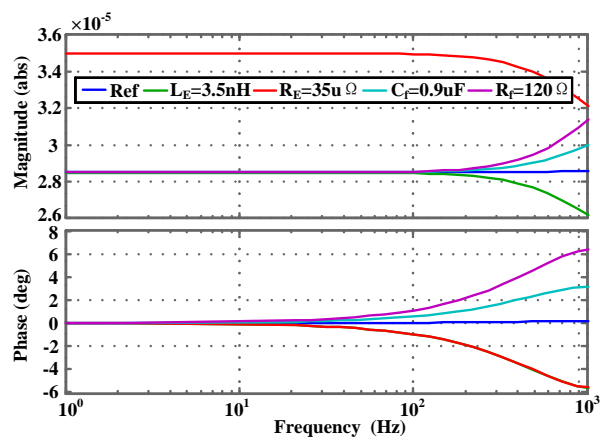

(a) low frequency.

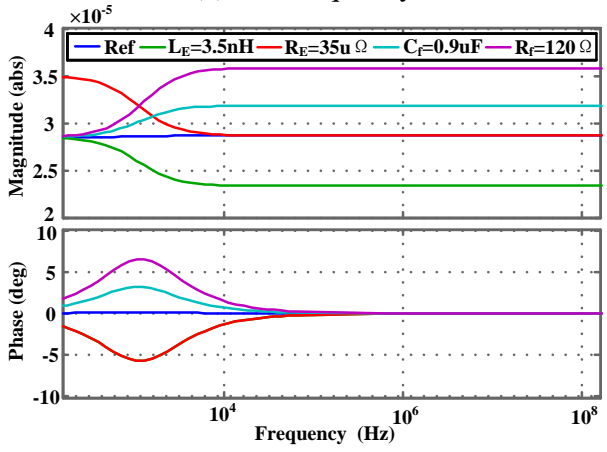

(b) high frequency.

Fig. 4. Analytic results of amplitude-frequency characteristics of $\mathrm{u}_{\mathrm{Cf}} / \mathrm{i}_{\mathrm{C}}$.

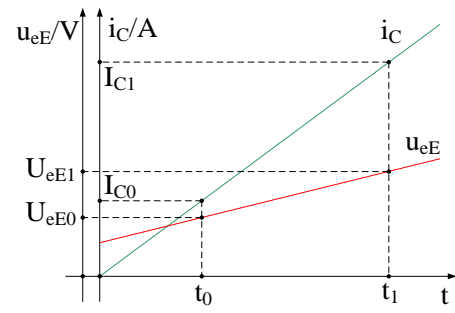

(a)

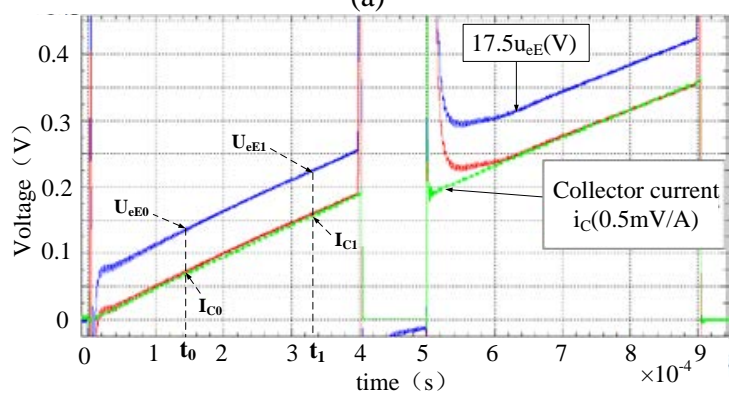

(b)

Fig. 5 Waveforms of collector current $\mathrm{i}_{\mathrm{C}}$ and voltage $\mathrm{u}_{\mathrm{Ee}}$ under double pulse test. 


$$
\left\{\begin{array}{l}
d i_{C} / d t=\left(I_{C 1}-I_{C 0}\right) /\left(t_{1}-t_{0}\right) \\
U_{e E 1}=I_{C 1} \cdot R_{E}+L_{E} \cdot d i_{C} / d t \\
U_{e E 0}=I_{C 0} \cdot R_{E}+L_{E} \cdot d i_{C} / d t
\end{array}\right.
$$

The following expressions (9), (10) are based (8) and the values of $L_{E}$ and $R_{E}$ can be determined.

$$
\begin{gathered}
R_{E}=\left(U_{e E 1}-U_{e E 0}\right) /\left(I_{C 1}-I_{C 0}\right) \\
L_{E}=-\left(U_{E e 0}+I_{C 0} \cdot R_{E}\right) \cdot\left(t_{1}-t_{0}\right) /\left(I_{C 1}-I_{C 0}\right)
\end{gathered}
$$

The waveforms of the injected collector current $\mathrm{i}_{\mathrm{C}}$ and voltage $\mathrm{u}_{\mathrm{Ee}}$ are shown in Fig. 5(b) under a double pulse test. This method is used for testing $\mathrm{L}_{\mathrm{E}}$ and $\mathrm{R}_{\mathrm{E}}$ of an Infineon IGBT FZ1500R33HL3. The results are $4.3 \mathrm{nH}$ and $28.5 \mu \Omega$, respectively. In addition, the range value of $L_{E}$ and $R_{E}$ of different modules of the same model are $3.6 \mathrm{nH}$ to $4.9 \mathrm{nH}$ and $24 \mu \Omega$ to $31.5 \mu \Omega$, respectively.

\section{EXPERIMENTAL STUDY OF IGBT COLLECTOR CURRENT ONLINE MEASUREMENT}

\section{A. The Test Platform for the IGBT Collector Current}

The corresponding test circuit based on the single-phase half-bridge topology is used for the experimental verification of the online measuring method of the IGBT collector current. The test platform for the IGBT collector current is shown in Fig. 6 and the test pulse shown in Fig. 7.

The switch tubes $\mathrm{T}_{1} \sim \mathrm{T} 2$ are Infineon Corporation's 3300V/1500A high-power IGBTs (model: FZ1500R33HL3) as shown in Fig. 6, whose driver contains the products of the CONCEPT Company (model: 1SD536F2). Tube T2 in Fig. 6 is the IGBT to be detected. The main purpose of using three pulses for the test is to compare the different pulse widths and verify the feasibility of the method to acquire the IGBT current based on the capacitor voltage under the conditions of whether the IGBT has a current or not before its conduction. The real objects on the test platform are shown in Fig. 8. A Tektronix 4-channel digital oscilloscope (model: DPO2024, 200MHz) is used in the test, which is powered by an isolated transformer. The collector current $i_{\mathrm{C}}$ or load current $i_{\text {load }}$ is measured by a flexible Rogowski coil (model: CWT60B, 0.50mV/A). The current estimation value $\mathrm{k} u_{\mathrm{Cf}}$ is measured by a Tektronix low-voltage passive probe (model: P2220, $200 \mathrm{MHz}$ bandwidth).

\section{B. The Test Results of the Collector Current of the IGBT Module under a Typical Load}

Various experiments are carried out under the condition of three kinds of loads (resistance-inductance load, resistance load, and inductance load) to verify the on-line measurement of the IGBT collector current by measuring the capacitor voltage.

1) The test results of the collector current at different bus voltages under a resistance inductance load: The two-stage amplifier scheme shown in Fig. 2 is used for testing the collector current under a resistance inductance load (load

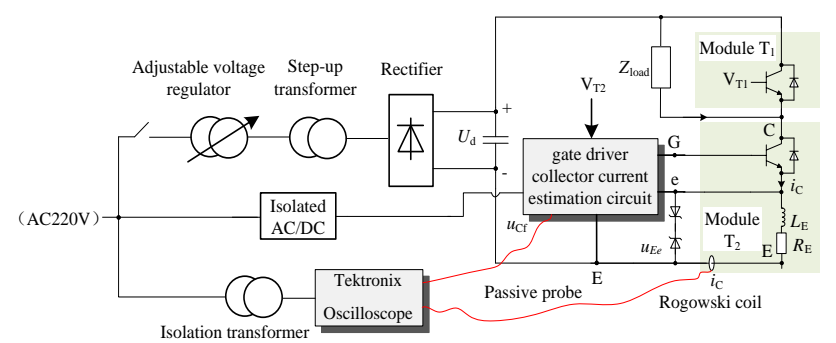

Fig. 6. The test platform for IGBT collector current.

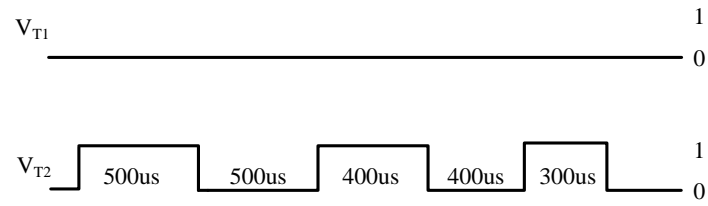

Fig. 7. The test pulse for IGBT collector current.

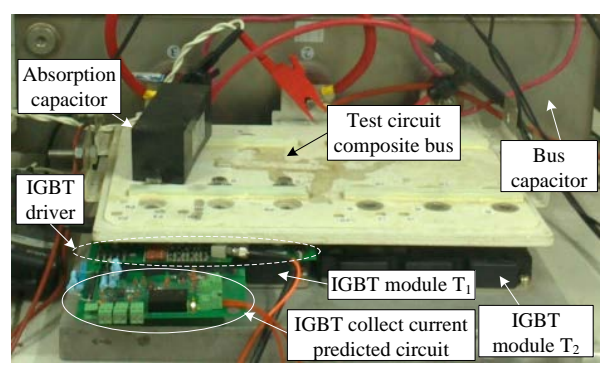

Fig. 8. The physical drawing of test platform for IGBT collector current.

inductance: $3 \mathrm{mH}$; load resistance: $8 \Omega$ ) and at bus voltages of $1 \mathrm{kv}$ and $2 \mathrm{kv}$, respectively. Due to limited space, a general drawing of the IGBT module and a detailed switching-transient and on-state diagram of the third pulse are only given as follows: the estimated value of the collector current of the IGBT module is obtained by using the capacitor voltage, and the measured value of the collector current represents the actual test current, like below.

Bus voltages of $1 \mathrm{kv}$ and $2 \mathrm{kv}$ tests are carried out under resistance-inductance load, respectively. And the results are shown in Fig. 9.

2) The Test Results of the Collector Current at Different Bus Voltages under a Resistance Load: Tests are carried out under a resistance load (load resistance: $8 \Omega$ ), and at bus voltages of $1 \mathrm{kv}$ and $2 \mathrm{kv}$, respectively. The results are as shown in Fig. 10.

There is a ripple in the oscilloscope or the probe under the conditions of a high voltage and a large current, as shown in Fig. 11. In addition, the given waveforms in the paper do not use a high frequency filter.

3) The Test Results of the Collector Current at Different Bus Voltages under an Inductance Load: Tests are carried out when the load inductance is $2 \mathrm{mH}$ and the bus voltages are $1 \mathrm{kV}, 1.5 \mathrm{kV}$, and $2 \mathrm{kV}$, respectively. The results are as shown in Fig. 12. 


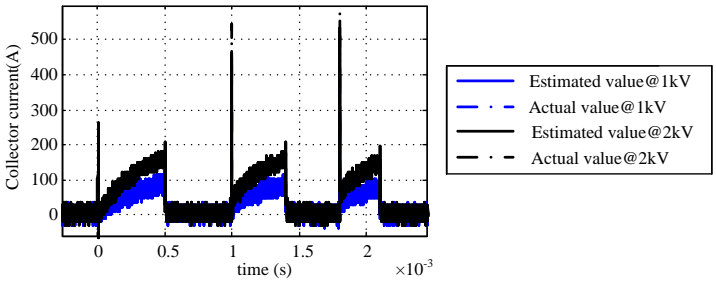

(a) General drawing.

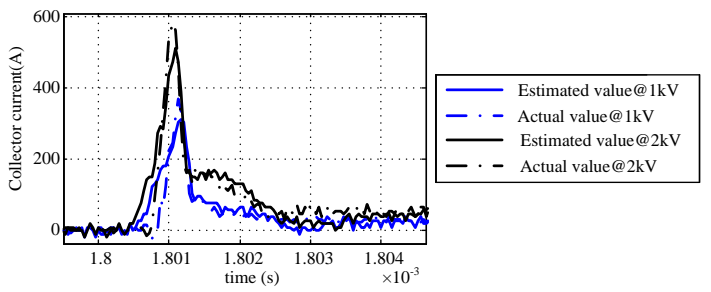

(b) The detailed diagram of the third pulse in a switching-on transient state.

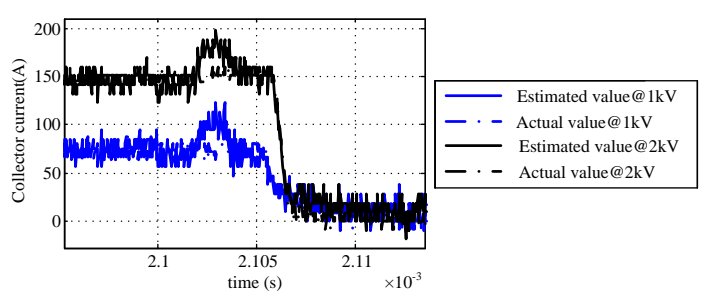

(c) The detailed diagram of the third pulse in a switching-off transient state.

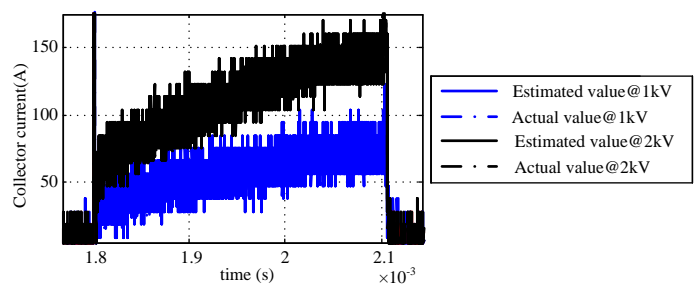

(d) The detailed on-state diagram of the third pulse.

Fig. 9. Test results of collector current at varied bus voltage under resistance-inductance load.

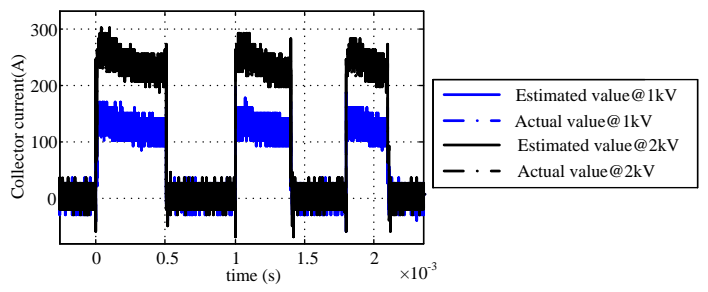

(a) General drawing.

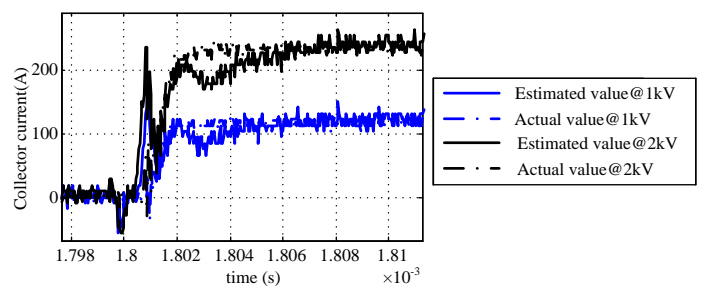

(b) The detailed diagram of the third pulse in a switching-on transient state.

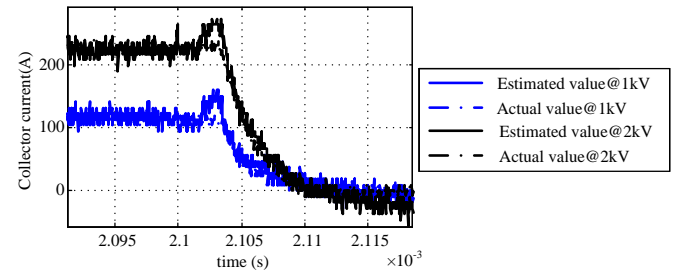

(c) The detailed diagram of the third pulse in a switching-off transient state.

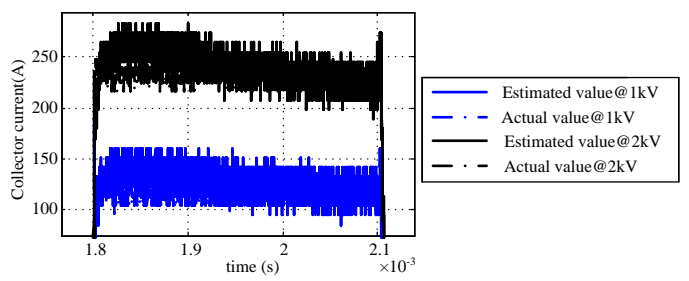

(d) The detailed on-state diagram of the third pulse.

Fig. 10. Test results of collector current at varied bus voltage under the resistance load of $8 \Omega$.

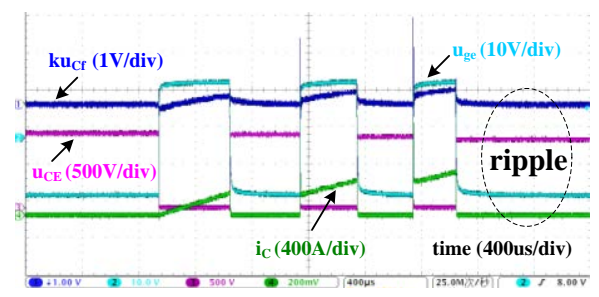

Fig. 11. Test results of collector current of bus voltage $1 \mathrm{kV}$ under the inductance load of $2 \mathrm{mH}$.

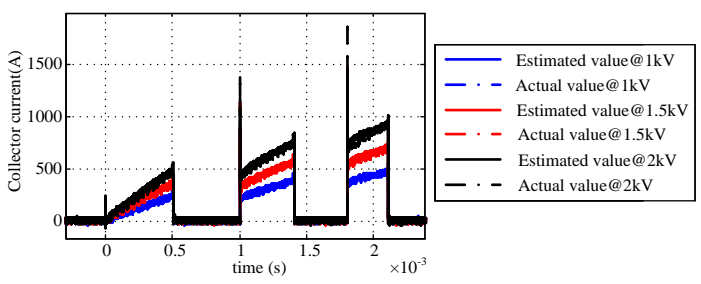

(a) General drawing.

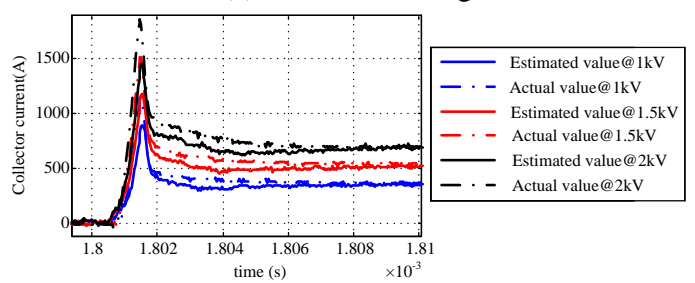

(b) The detailed diagram of the third pulse in a switching-on transient state.

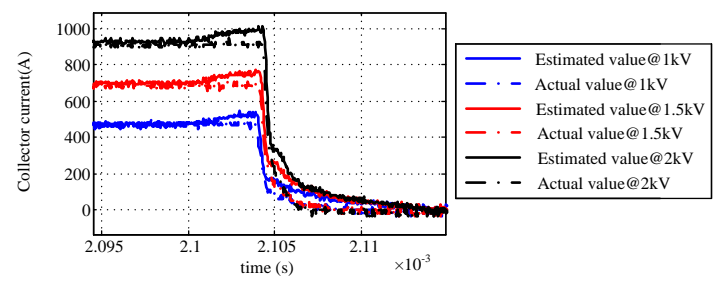

(c) The detailed diagram of the third pulse in a switching -off transient state. 


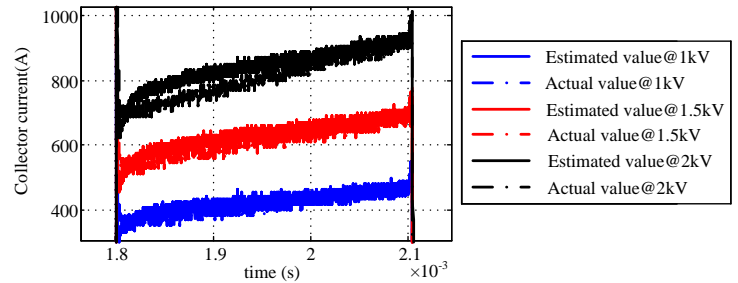

(d) The detailed on-state diagram of the third pulse.

Fig. 12. Test results of collector current of varied bus voltage under the inductance load of $2 \mathrm{mH}$.

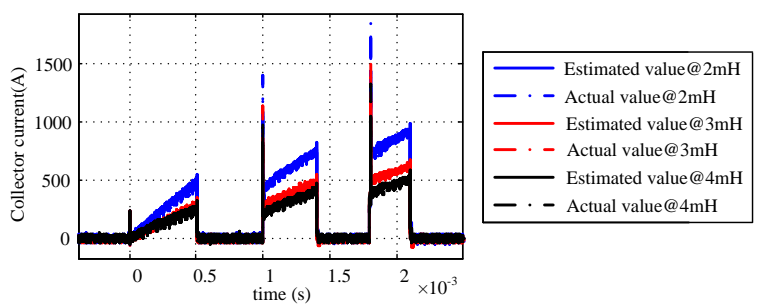

(a) General drawing.

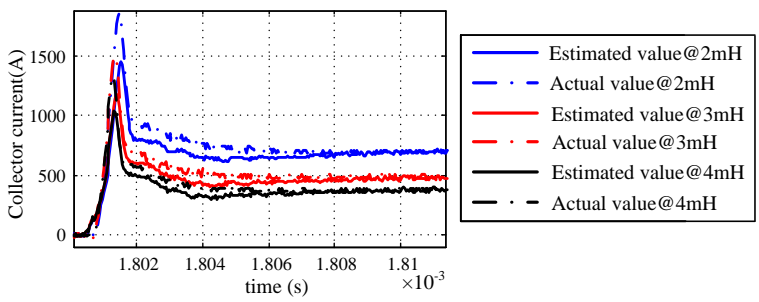

(b) The detailed diagram of the third pulse in a switching-on transient state.

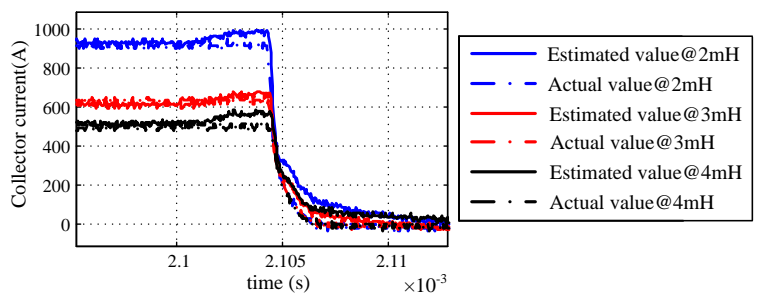

(c) The detailed diagram of the third pulse in a switching-off transient state.

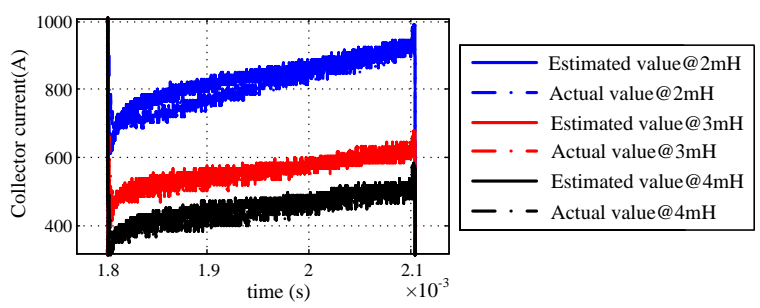

(d) The detailed on-state diagram of the third pulse.

Fig. 13. Experimental waveforms of varied inductance loads at the bus voltage of $2 \mathrm{kV}$.

\section{1) The Test Results of the Collector Current at a Bus Voltage of $2 \mathrm{kV}$ under Different Inductance Loads}

Tests are carried out when the bus voltage is $2000 \mathrm{~V}$ and the inductance loads are $2 \mathrm{mH}, 3 \mathrm{mH}$, and $4 \mathrm{mH}$, respectively. The results are shown in Fig. 13.
It can be seen from Fig. 9 to Fig. 13 that the collector current estimated by use of the capacitance voltage basically conforms to the actual collector current when the IGBT is in the on-state, and that the estimated collector current trends to be similar to the actual collector current but with an amplitude that is small when the IGBT is in a switching transient. The cause analysis is as follows: The IGBT module used for testing consists of three IGBTs which are combined into a whole by the installed bus. Therefore, its power emitter resistor $R_{\mathrm{E}}$ and power emitter inductance $L_{\mathrm{E}}$ serve as distributed parameters because of the three IGBTs in parallel. The internal circuit of the testing IGBT is shown as shown in Fig.14.

The experimental results show that the IGBT module power emitter inductance $L_{\mathrm{E}}$ has decreased while $R_{\mathrm{f}} C_{\mathrm{f}}$ basically remained unchanged when the IGBT is in a switching transient. In this case, the expression for the collector current estimation should be $R_{\mathrm{f}} C_{\mathrm{f}} u_{\mathrm{Cf}} / L_{\mathrm{E}}$. However, expression (6) is still used for collector current estimation. For $R_{\mathrm{E}}<L_{\mathrm{E}} /\left(R_{\mathrm{f}} C_{\mathrm{f}}\right)$, the value estimated of collector current in a transient state is a little small, as shown in Fig. 3(c). It is obvious that the amplitude of $\mathrm{u}_{\mathrm{Cf}} / \mathrm{i}_{\mathrm{C}}$ will decrease from $R_{\mathrm{E}}$ to $L_{\mathrm{E}} /\left(R_{\mathrm{f}} C_{\mathrm{f}}\right)$ when the angular frequency $\omega$ is greater than $R_{\mathrm{E}} / L_{\mathrm{E}}$.

2) The Test Results of the Collector Current at Different IGBT Junction Temperatures: When the bus voltage is $2000 \mathrm{~V}$ and the load inductance is $2 \mathrm{mH}$, tests are made at IGBT junction temperatures of $25^{\circ} \mathrm{C}, 60^{\circ} \mathrm{C}$, and $120^{\circ} \mathrm{C}$, respectively. The results are as shown in Fig. 15.

The test results obtained at different IGBT junction temperatures show that the error in the estimation of the collector current of the IGBT module according to the capacitance voltage becomes large with an increase in the junction temperature. For example, the error in the estimation of the on-state collector current is about $20 \%$ when the IGBT junction temperature changes from $25^{\circ} \mathrm{C}$ to $120^{\circ} \mathrm{C}$. This is due to the fact that an increase in the IGBT junction temperature results in an increase in the resistance value $R_{\mathrm{E}}$ of the IGBT power-emitter copper conduction terminal. The relationship between the copper resistivity and the temperature is generally expressed as follows:

$$
\rho=\rho_{0}(1+\alpha T)
$$

where $\rho_{0}$ is the resistivity of the temperature $0^{\circ} \mathrm{C}$, and $\alpha$ is the temperature coefficient of the copper with a range of values from 0.002 to 0.0039 . According to (11), when the temperature rises to about $95^{\circ} \mathrm{C}$, the resistance value of the copper increases by about $19 \% \sim 37 \%$, which amounts to the actually-estimated value of the collector current.

\section{The Test Results of the Collector Current of an IGBT Module under a Typical Load with a Filter}

Under the condition of three typical loads and different junction temperatures, the tests of collector currents have been carried out by using a filter. The results are obtained, as shown 


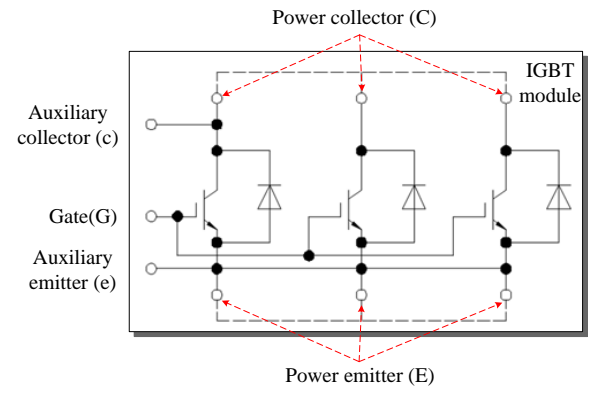

Fig. 14. The internal circuit of testing IGBT.

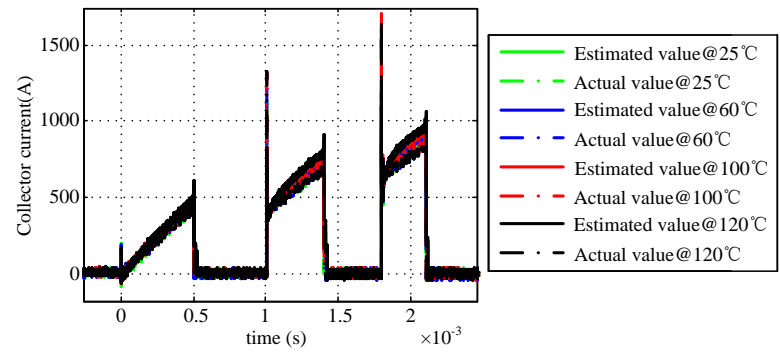

(a) General drawing.

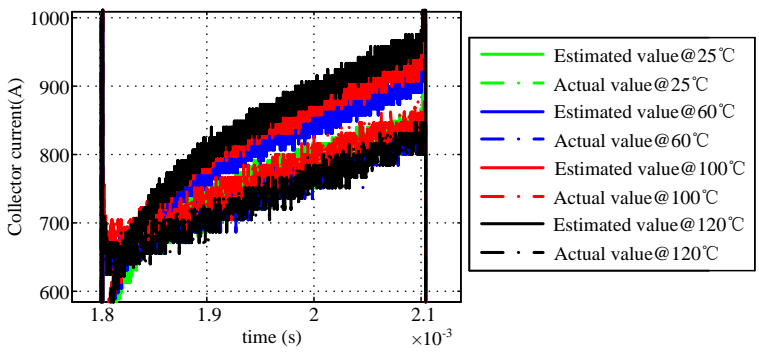

(b) The detailed diagram of the third pulse in a switching-on transient state.

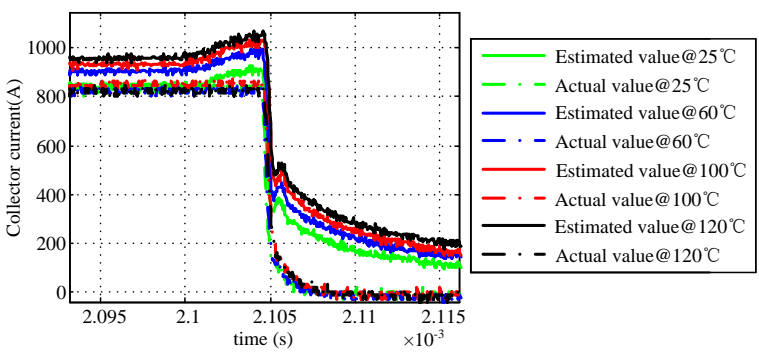

(c) The detailed diagram of the third pulse in a switching-off transient state.

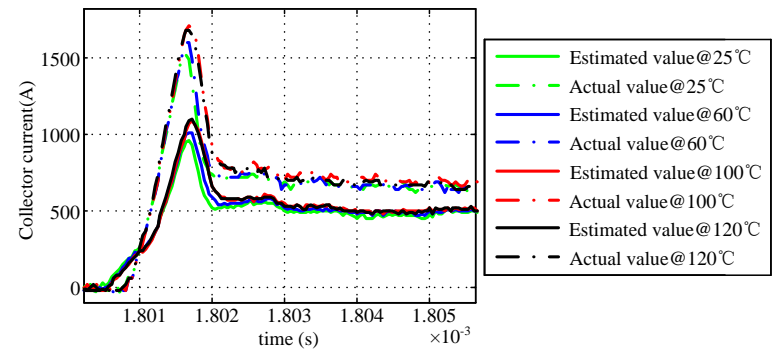

(d) The detailed on-state diagram of the third pulse.

Fig. 15. Test results at different junction temperatures in the conditions of bus voltage $2 \mathrm{kV}$ and load inductance $2 \mathrm{mH}$. in Fig. 16 to Fig. 20. Due to limited space, general drawings of the IGBT module and a detailed on-state diagram of the third

pulse are only given as follows: The estimated value of the IGBT module collector current is obtained by using the capacitor voltage, and the actual value of the collector current represents the actual current tested.

1) The Test Results of Collector Current at Different Bus Voltages under Inductance Load with a Filter: Different bus voltages tests are carried out under the inductance load of $2 \mathrm{mH}$ with filter. And the results are shown in Fig. 16.

2) The Test Results of Collector Current at Different Bus Voltages under a Resistance Load with a Filter: Different bus voltages tests are carried out under the resistance load of $8 \Omega$ with filter. And the results are shown in Fig. 17.

3) The Test Results of Collector Current at Different Bus Voltages under a Resistance Inductance Load with a Filter: Different bus voltages tests are carried out under a resistance inductance with a filter. And the results are shown in Fig. 18.

4) The Test Results of Collector Current at the Bus Voltage of $2 k V$ under Different Inductance Loads with a Filter: The bus voltage of $2 \mathrm{kV}$ tests are carried out under different inductance loads with a filter. And the results are shown in Fig. 19.

5) The Test Results of Collector Current at Different IGBT Junction Temperatures with a Filter: The conditions of bus voltage $2 \mathrm{kV}$ and load inductance $2 \mathrm{mH}$ with filter tests are carried out under different IGBT junction temperatures. And the results are shown in Fig. 20.

It can be seen in Fig. 16 to Fig. 20 that there is some ripple in the estimated value and actual value of the collector current when a filter is not used, and that there is little ripple when a filter is used. From the above contrast test results, it is concluded that the test current estimated by use of the capacitor voltage basically conforms with the actual collector current.

\section{The Test Results of IGBT Module Collector Current under Soft Short-Circuit and Hard Short-Circuit Conditions}

Test are carried out under the conditions of soft and hard short circuits with different bus voltages based on the single-phase half-bridge inverter circuit, as shown in Fig. 6. This is done to verify the accuracy of estimating IGBT module collector current by the use of capacitor voltage $u_{\mathrm{Cf}}$ under short-circuit conditions.

Note: Considering that the amplitude of $u_{\mathrm{Cf}}$ is relatively large in the short-circuit case, the magnifying multiples set for the measuring circuit of the collector current should be different under normal and short-circuit conditions in order to improve the accuracy of the measurement. The reason for this setting is that the oscilloscope probe is not so high in accuracy. As a result, the measurement of a small signal is easily subjected to interference. Therefore, another circuit scheme is adopted for digital acquisition with a 12-bit high-speed $\mathrm{A} / \mathrm{D}$ chip to meet the requirements of accurate 


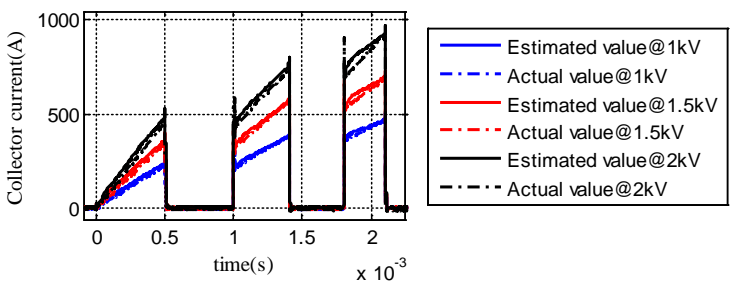

(a) General drawing with filter.

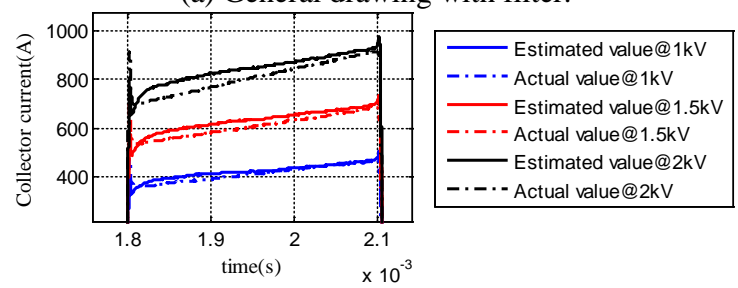

(b) The detailed on-state diagram of the third pulse with filter.

Fig. 16. Test results of collector current of varied bus voltage under the inductance load of $2 \mathrm{mH}$ with filter.

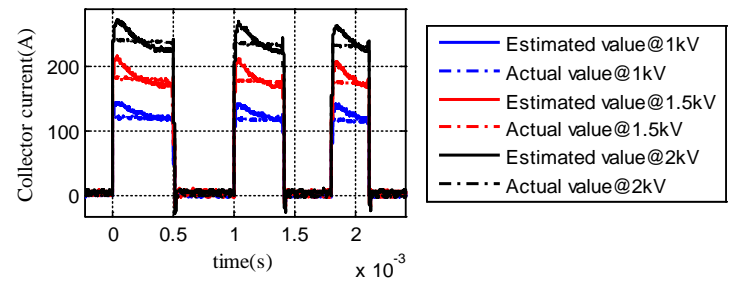

(a) General drawing with filter.

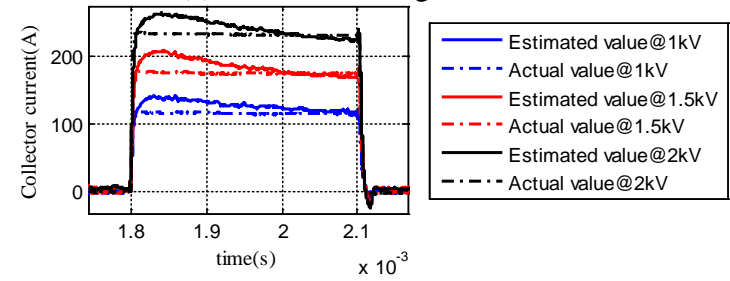

(b) The detailed on-state diagram of the third pulse with filter.

Fig. 17. Test results of collector current at varied bus voltage under the resistance load of $8 \Omega$ with filter.

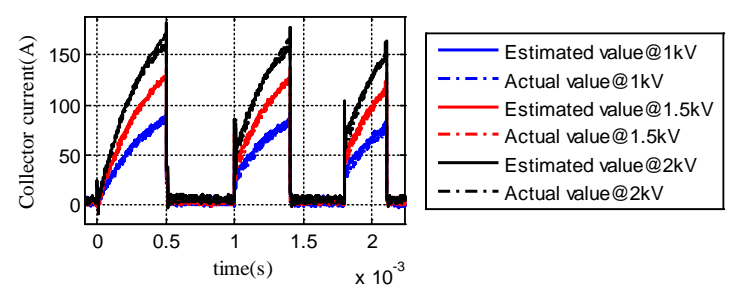

(a) General drawing with filter.

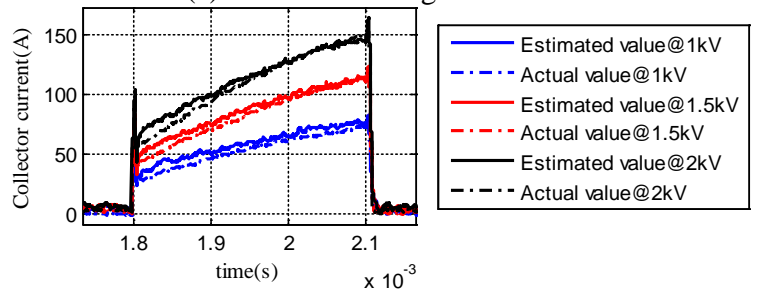

(b) The detailed on-state diagram of the third pulse with filter.

Fig. 18. Test results of collector current at varied bus voltage under resistance-inductance load with filter.

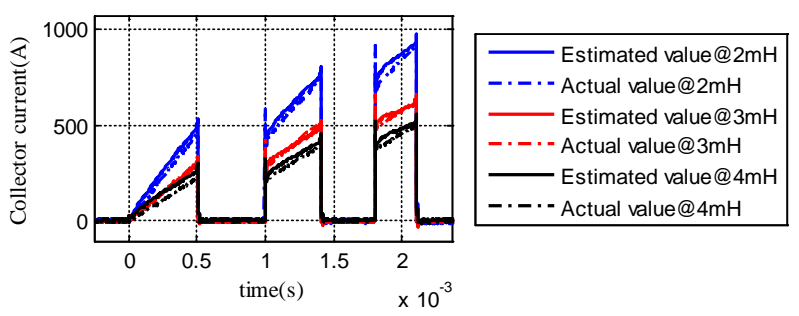

(a) General drawing with filter.

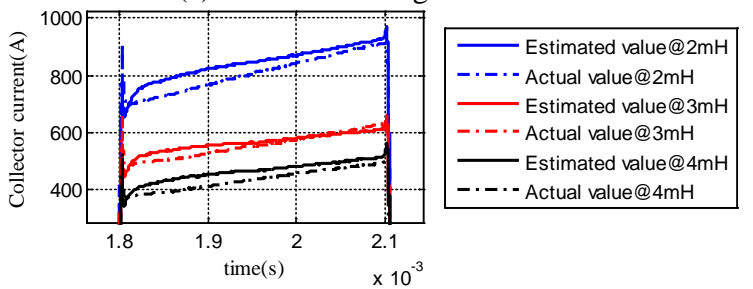

(b) The detailed on-state diagram of the third pulse with filter.

Fig. 19 Experimental waveforms of varied inductance loads at the bus voltage of $2 \mathrm{kV}$ with filter.

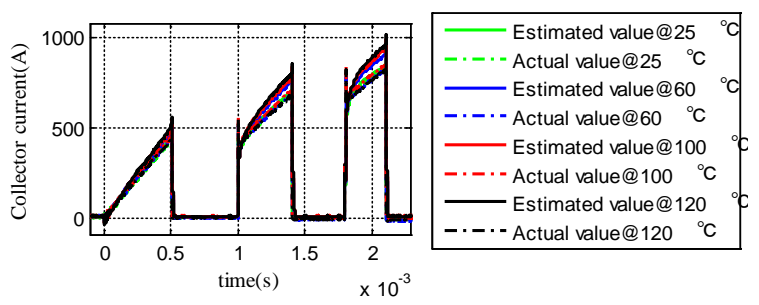

(a) General drawing with filter.

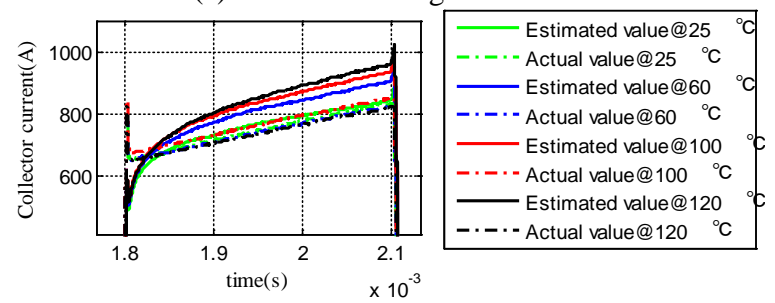

(b) The detailed on-state diagram of the third pulse with filter.

Fig. 20. Test results at different junction temperatures in the conditions of bus voltage $2 \mathrm{kV}$ and load inductance $2 \mathrm{mH}$ with filter.

measurement of $u_{\mathrm{Cf}}$ under normal and short-circuit conditions through magnification.

1) The Test Results of Hard Short Circuits at Different Bus Voltages: Hard short-circuit tests are carried out under different bus voltages according to the scheme shown in Fig.

2. The results are shown in Fig. 21.

Hard short-circuit tests are also carried out under different bus voltages. The results show that the estimated value of the collector current tends to be the same as the actual value but the amplitude is a little small. A slow decrease in the estimated value of the collector current after the turn-off of the IGBT is mainly because the chip discharges a little slowly.

Fig. 22 shows the preserved oscilloscope waveform in the hard short-circuit test at a bus voltage of $2.2 \mathrm{kV}$.

In Fig. 22, $u_{\mathrm{CE}}$ and $u_{\text {ge }}$ denote the collector voltage and gate 


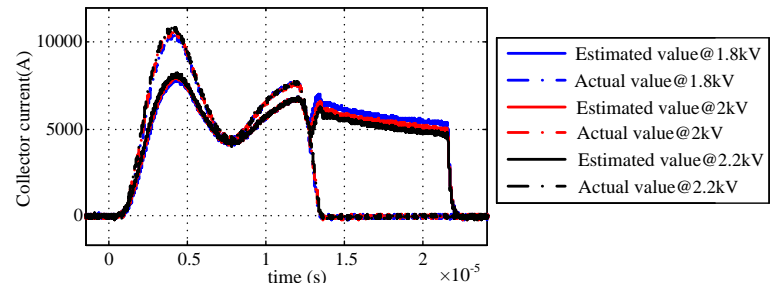

Fig. 21. Test results of collector current at varied bus voltage in hard short circuit.

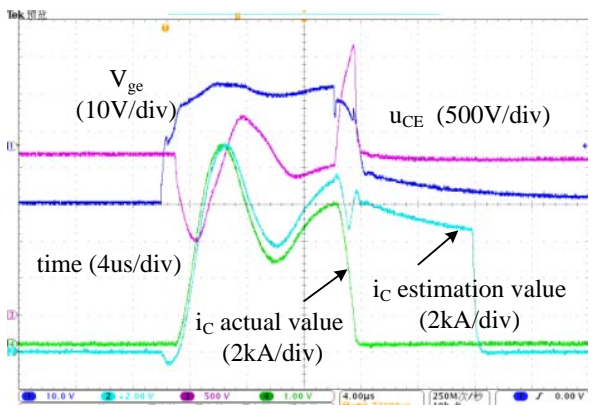

Fig. 22. The preserved oscilloscope waveform in the hard short-circuit test at bus voltage $2.2 \mathrm{kV}$.

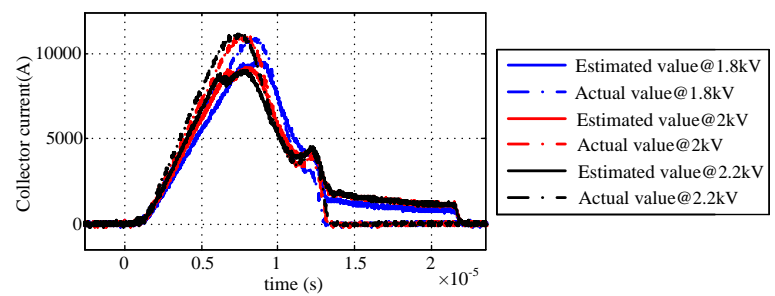

Fig. 23. Test results of collector current in soft short circuit at varied bus voltage.

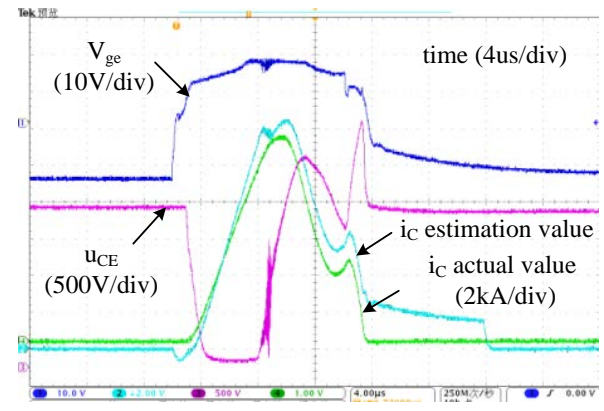

Fig. 24. The preserved oscilloscope waveform in the soft short-circuit test at bus voltage $2.2 \mathrm{kV}$.

drive voltage of tube $T_{2} . i_{C}$ is the forward-conduction current of tube $\mathrm{T}_{2}$, and $\mathrm{k} u_{\mathrm{Cf}}$ is the output voltage of the current measuring circuit. It is easy to see that the output voltage $\mathrm{k} u_{\mathrm{Cf}}$ of the current measuring circuit has a tendency to conform to $i_{\mathrm{C}}$ after the conduction of the IGBT, as shown in Fig. 22.

2) The Test Results of Soft Short Circuits at Different Bus Voltages: Soft short-circuit tests are carried out under different bus voltages. The results are shown in Fig. 23.

Soft short-circuit tests are also carried out under different bus voltages. The results show that the estimated value of the collector current is basically the same as the actual value, but the amplitude is a little small.

Fig. 24 shows the preserved oscilloscope waveforms in the soft short-circuit test at a bus voltage of $2.2 \mathrm{kV}$.

Hard and soft short-circuit tests are carried out at different bus voltages. The results show that the estimation of the IGBT collector current can be fulfilled by using voltage $u_{\mathrm{Cf}}$ at the time of a short-circuit fault. The estimated value of the collector current is basically equivalent to the actual value, but the amplitude is a little small.

\section{E. Summing-Up the Tests of the IGBT Module Collector Current}

(1) It is difficult to achieve a large amplification of a signal and make it meet the target of a higher bandwidth by using the conventional single-stage op-amp amplification scheme. However, the use of a two-stage operational amplifier can meet the requirement of measuring a small signal with a large gain and a high bandwidth.

(2) Various tests are carried out under the conditions of several typical loads, different junction temperatures, and soft and hard short circuits. The results show that capacitance voltage $u_{\mathrm{Cf}}$ can be used to fulfill the estimation of the on-state collector current of the IGBT, and that for the switching-on transient collector current of the IGBT, the estimated collector current tends to be similar to the actual collector current, but the amplitude is a little small. The main reason is that the IGBT module power emitter inductance is a distributed inductance, whose value will decrease at high frequencies.

(3) The results of the tests performed at different IGBT junction temperatures show that the accuracy of the collector current estimation according to the capacitance voltage will decrease and that the error in the estimation of the on-state collector current is about $20 \%$ when the IGBT junction temperature changes from $25^{\circ} \mathrm{C}$ to $120^{\circ} \mathrm{C}$.

\section{CONCLUSION}

This paper proposed a concrete circuit for the non-intervention on-line measurement of IGBT collector current by detecting the voltage drop of the IGBT power emitter and auxiliary emitter terminals. This circuit uses an operational amplifier for impedance isolation to avoid the bad influence of the measuring circuit on the dynamic performance of the IGBT. The adoption of a scheme for integration first and amplification afterwards solves the problem of the conventional probe being unable to meet the requirement of accurate transient and on-state measurement at the voltage drop of the power emitter and auxiliary emitter. On this basis, the use of the two-stage operational amplifier meets the demand for high-bandwidth measurement of a small signal with a large gain. Finally, various experiments are made under the 
condition of several typical loads (resistance-inductance load, resistance load, and inductance load), different IGBT junction temperatures, and soft and hard short circuits. The results show that the proposed method based on the capacitor voltage for the on-line measurement of the IGBT collector current is correct and feasible. Therefore, this method may be of certain reference value in terms of the sensor-free control of the large-power converter hierarchical control of IGBT drivers and the short-circuit and overcurrent protection of IGBTs.

\section{ACKNOWLEDGMENT}

This work was supported by the National Natural Science Foundation of China (NSFC) under Grant 51177170.

\section{REFERENCES}

[1] C. Sun, C. Zhang and S. Ai, "A practical high-speed fiber ring net topology and protocol for large-capacity power electronic systems," Proceedings of the CSEE, Vol. 32, No. 2, pp. 63-73, May. 2012.

[2] R. S. Chokhawala, J. Catt, and B. Pelly, "Gate drive considerations for IGBT modules,” IEEE Trans. Ind. Appl., Vol. 31, No, 3, pp.603-611, May/Jun. 1995.

[3] V. John, B. Suh and T. A. Lipo, "High performance active gate drive for high power IGBTs,” IEEE Trans. Ind. Appl., Vol. 35, No. 5, pp.1108-1117, Sep./Oct. 1999.

[4] D. Bortis, P. Steiner, and J. Biela, "Double-stage gate drive circuit for parallel connected IGBT modules,” IEEE Trans. Dielectr. Electr. Insul., Vol. 16, No. 4, pp.1020-1027, Aug. 2009.

[5] N. Idir, R. Bausière and J. and J. Franchaud, “Active gate voltage control of turn-on di/dt and turn-off $\mathrm{dv} / \mathrm{dt}$ in insulated gate transistors," IEEE Trans. Power Electron. Vol. 21, No. 4, pp. 849-855, Jul. 2006.

[6] P. Shihong and T.M. Jahns, "Flexible dv/dt and di/dt control method for insulated gate power switches," Industry Applications Conference, $36^{\text {th }}$ IAS Meeting, IEEE, Vol. 2, pp. 1038-1045, Sep./Oct. 2001.

[7] H.Kuhn, T.Köneke and A.Mertens, "Considerations for a digital gate unit in high power applications," Power Electronics Specialists Conference PESC'08, Rhodos, Greece, pp.2784-2790, Jun. 2008.

[8] C. SUN, "The study of technology related to digital active gate drive considerations in distributed control function integrate,” the National Natural Science Foundation on the project application, 2011.

[9] N. Idir, R. Bausière and J. J. Franchaud, “Active gate voltage control of turn-on di/dt and turn-off $\mathrm{dv} / \mathrm{dt}$ in insulated gate transistors," IEEE Trans. Power Electron., Vol. 21, No. 4, pp. 849-855, Jul. 2006.

[10] Y. Wang, P. R. Palmer, A. T. Bryant, and S. J. Finney, "An analysis of high-power IGBT switching under cascade active voltage control,” IEEE Trans. Ind. Appl., Vol. 45, No. 2, pp. 861-870, Mar./Apr. 2009.

[11] M A Rodríguez-Blanco, A Claudio-Sánchez, and D. Theilliol, "A failure-detection strategy for IGBT based on gate-voltage behavior applied to a motor drive system," IEEE Trans. Ind. Electron., Vol. 58, No. 5, pp. 1625-1633, May 2011.
[12] Y. Lobsiger and J. W. Kolar, "Voltage, current and temperature measurement concepts enabling intelligent gate drives," ECPE Workship, Electronics around the power switch: Gate Drivers, Sensor and Control, Munich, Germany, Jun. 2011.

[13] C. Schott, H. Blanchard, R. S. Popovic, and R. Racz, "High accuracy analog hall probe,” IEEE Trans. Instrum. Meas., Vol. 46, No. 2, pp. 613-616, Apr. 1997.

[14] N. McNeill, N. K. Gupta, and W. G. Armstrong, "Active current transformer circuits for low distortion sensing in switched mode power converters," IEEE Trans. Power Electron., Vol. 19, No. 4, pp. 908-917, Jul. 2004.

[15] M. Zhu, D. J. Perreault, V. Caliskan, and T. C. Neugebauer, "Design and evaluation of feedforward active ripple filters," IEEE Trans. Power Electron., Vol. 20, No. 2, pp. 276-285, Mar. 2005.

[16] C. Xiao, L. Zhao, and T. Asada, "An overview of integratable current sensor technologies," Proc. of the 38th IEEE Industry Applications Society Annual Meeting (IAS), Vol. 2, pp.1251-1258, Oct. 2003.

[17] D. Gerber, T. Guillod, R. Leutwyler, and J. Biela, "Gate unit with improved short-circuit detection and turn-off capability for 4.5-kV press-pack IGBTs operation at 4-kA pulse current,” IEEE Trans. Plasma Sci. Vol. 41, No. 10, pp. 2641-2648, Oct. 2013.

[18] R. Slatter, J. Schmitt and G. V. Manteuffel, "Highly dynamic Current sensors based on Magneto Resistive (MR) technology," Proc. of the Power Conversion Intelligent Motion Conf. (PCIM Europe), pp.616-620, 2011.

[19] H. N. Shah, Y. Xiao, T. P. Chow, and R. J. Gutmann, "Power electronics modules for inverter applications using flip-chip on flex-circuit technology," Proc. of the 39th IEEE Industry Applications Society Annual Meeting (IAS), Vol. 3, pp.1526-1533, Oct. 2004.

[20] E. R. Motto and J. F. Donlon, "New compact IGBT modules with integrated current and temperature sensors," Powerex technical library, 2005.

[21] Y. Lobsiger and J. W. Kolar, "Closed-loop di/dt \& dv/dt control and dead time minimization of IGBTs in bridge leg configuration," Control and Modeling for Power Electronics (COMPEL), pp.1-7, Jun. 2013.

[22] V. John, “Active gate drive circuits for IGBTs,” University Of Wisconsin, Madison, 1999.

[23] Z. Wang, X. Shi, L. M. Tolbert, and J. B. Benjamin, “A fast overcurrent protection scheme for IGBT modules through dynamic fault current evaluation," in IEEE Applied Power Electronics Conference and Exposition, pp.577-583, Mar. 2013.

[24] Y. Deng, Z. M. Zhao, L. Q. Yuan, S. D Hu, and X. S. Wang, "IGBT model for analysis of complicated circuits," Proceedings of the CSEE, Vol. 30, No. 9, pp. 1-7, Mar. 2010.

[25] Y. Lobsiger and J. W. Kolar, "Stability and robustness analysis of $\mathrm{d} / \mathrm{dt}$-closed-loop IGBT gate drive," Proc. the 28th Applied Power Electronics Conference and Exposition (APEC2013), California, USA, pp. 2682-2689, Mar. 2013.

[26] H. Lei and L. Shiguo, "Design considerations of time constant mismatch problem for inductor DCR current sensing method," in 21st Annual IEEE Applied Power Electronic Conference and Exposition, Mar. 2006.

[27] A. M. Patel and M. Ferdowsi, "Advanced current sensing techniques for power electronic converters," in IEEE Vehicular Power and Propulsion Conference, Arlington, Texas, pp. 524-530, Sep. 2007. 


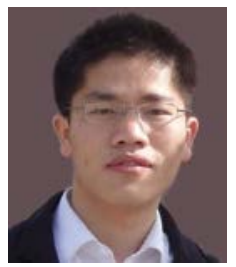

Liangdeng Hu was born in 1986. He received his M.S. and Ph.D. degrees in Electrical Engineering from the Naval University of Engineering, Wuhan, China, in 2010 and 2015, respectively. Dr. $\mathrm{Hu}$ is presently working as a Lecturer with Naval University of Engineering. His current research interests include medium-high voltage and large-capacity power electronic converter technologies, and high power IGBT digital gate drive technologies.

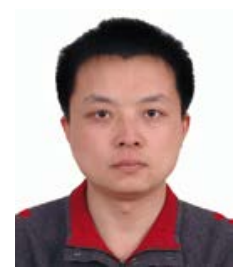

Chi Sun was born in 1977. He received his M.S. degree in Power Electronic and Electric Drive at the Radar Institute of Air Force, Wuhan, China, in 2001; and his Ph.D. degree in Weapon Systems and Applications at the Ordnance Engineering College, Shijiazhuang, China, in 2004. Dr. Sun is presently working as a Professor and Supervisor for Ph.D. candidates at the Naval University of Engineering, Wuhan, China. His current research interests include medium-high voltage and large-capacity power electronic converter technologies and control-related technologies.

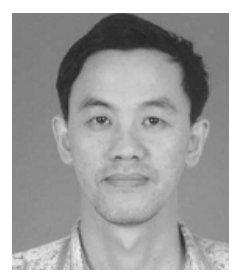

Zhihua Zhao was born in 1962. He received his M.S. degree in Physics from the Chinese Academy of Science, Beijing, China, in 1990; and his Ph.D. degree in Electrical Engineering from Tsinghua University, Beijing, China, in 2006. Dr. Zhao is presently working as a Professor and Supervisor for Ph.D. candidates with the Naval University of Engineering, Wuhan, China. His current research interests include the analysis and computation of electromagnetic fields and electromagnetic compatibility. 